\title{
How to Measure Technology Intelligence?
}

\author{
Ying Wan Loh*a, \\ Email: yingwanloh@cantab.net \\ Letizia Mortara ${ }^{a}$ \\ Email:1m367@cam.ac.uk
}

Institute for Manufacturing, Department of Engineering, University of Cambridge, 17

Charles Babbage Road, Cambridge CB3 OFS, UK

*Corresponding author

\begin{abstract}
Technology intelligence (TI) is an activity that supports decision-making at many levels. However, practitioners often find that evaluating the quality of TI activities can be very challenging. Whilst several papers in current literature discuss performance assessments in innovation contexts, less research specifically addresses the issue of performance measurement for TI. This paper aims to start to fill this gap by developing empirical evidence about the current evaluation methods adopted in industry, and the challenges posed by those metrics in assessing TI. A framework is proposed, which suggests that the metrics used for TI follow two logics: the first is that they are activity- or outcome-based, and the second is that they apply either to specific projects or to the entire firm. This classification of metrics could also help practitioners structure their future measuring and evaluating strategies.
\end{abstract}

Keywords: Technology intelligence; technology scouting; performance measure; assessment; evaluation; metrics; decision-making; open innovation; information quality; innovation management measurement; efficiency; effectiveness. 
Biographical Notes: Ying Wan Loh completed her Master's programme (MPhil) in Industrial Systems, Manufacture and Management at the Institute for Manufacturing, University of Cambridge in 2014. This work was part of her Master's dissertation. Prior to starting the Master's programme in Cambridge, she graduated from the University of Glasgow with a BEng (First Class Honours) in Mechanical Design Engineering. She is currently working for a British aerospace company.

Letizia Mortara is a Senior Research Associate at the University of Cambridge and a By-Fellow at Churchill College, Cambridge. She is also an Associate Editor for the R\&D Management journal. She has worked within the Centre for Technology Management at the Institute for Manufacturing since 2005. Prior to this, she gained her first degree in Industrial Chemistry at the University of Bologna in Italy. After spending three years working as a process/product manager in the chemical industry, she moved to the UK where she gained her $\mathrm{PhD}$ in processing and process scale-up of advanced ceramic materials at Cranfield University. Letizia's research focuses on understanding how companies implement open innovation and keep abreast of the latest developments in technology. She is also currently focusing on additive manufacturing technologies (3D Printing) in manufacturing and their implications for business. 
How to Measure Technology Intelligence?

\section{Introduction}

Technology intelligence (TI) is defined as "the capture and delivery of technological information as part of the process whereby an organisation develops an awareness of technology threats and opportunities" (Kerr et al., 2006, p.75). TI responds to a broad set of decision-making needs (from strategic to operational), as it helps a firm become aware of important developments in technologies (Kerr et al., 2006). Amongst other activities, TI could support innovation processes and, for instance, enable the identification of prospective partners with interesting technological knowledge (Mortara et al., 2010), or could be used to identify technology commercialisation opportunities (Rohrbeck, 2007).

The importance of having evaluation approaches in place for intelligence systems has been recognised across several literature domains. Neely et al. were amongst the first to think about the measurement of technological information and illustrated, with a case study, that technology assessment forms could be used to identify emerging technologies (Neely et al., 1997). The competitive intelligence $(\mathrm{CI})$ literature - i.e. the literature about "the process of developing actionable foresight regarding competitive dynamics and non-market factors that can be used to enhance competitive advantage" (Prescott, 1999, p.42) - suggests that performance indicators are important, because CI could absorb considerable budget and, hence, managers would be interested in proving that the intelligence function is making a contribution to the company's performance (West, 2001). This notion can also be applied to TI (Davison, 2001), and appropriate evaluation would offer some form of protection to intelligence practitioners when the next round of redundancy is being considered (West, 2001). Similarly, in the field of business intelligence (BI) - which regards a "system that combines data gathering, data storage, and knowledge management with analysis to provide input to the decision process" (Negash \& Gray, 2008, p.175) - Lönnqvist \& Pirttimäki argued that measuring BI is useful to both manage the BI process and to determine its value (Lönnqvist \& Pirttimäki, 2006). Although these authors proposed steps to design performance measures, they also admit that actual performance measures have not been presented and the literature lacks input from the real world. In the TI field, Kerr et al. pointed out that TI metrics should measure both the quality and value of TI, and went on to propose using measures derived from the information quality (IQ) literature to assess TI (Kerr et al., 2006). However, they did not test whether these metrics could be practically implemented. 
Instead, most works discussing metrics do so in other contexts. For instance, scholars studied innovation performance measurement (Adams et al., 2006; Dewangan \& Godse, 2014), whilst a number of recent papers have specifically addressed performance measurement issues for Open Innovation (OI) (Rogo et al., 2014; Huizingh, 2011; Enkel et al., 2011; Chesbrough, 2004). However, although the search for technological partners through TI is an important step in OI (Mortara et al. 2010), research has not yet discussed how companies evaluate the impact on the information gathered through intelligence for OI.

Hence, this paper aims to start filling this gap with an empirical study which reviews the measurement approaches companies currently adopt for TI and the practical challenges in this respect.

This paper is organised as follows: Section 2 presents the literature review on performance measurement in TI, and an analytical framework based on existing theory; Section 3 describes the research methodology, and Section 4 presents the data obtained from the interviews with professional managers involved with TI; Section 5 derives a framework for the assessment of TI in practice, and discusses its implications for theory and practice; finally, Section 6 summarises the conclusions and the limitations of this work.

\section{Literature Review}

In literature, many different terms are used to describe technology intelligence (TI), such as technology monitoring, technology forecasting, technology scanning and technology assessment (Lichtenthaler, 2004a; Kerr et al., 2006). However, they all refer to the knowledgegathering and dissemination process, where technology is the main topic of concern. In reality, every company practises TI in a different and unique way to fulfil their business needs: Reger argued that many TI activities are carried out informally by gatekeepers (Reger, 2001) while Lichtenthaler proved that TI could be organised in layers of structural, hybrid and informal coordination (Lichtenthaler, 2004a). Industry (Lichtenthaler, 2004b) and country-specific (Mortara et al., 2009) reviews show that, activities included under the umbrella of TI range, from the development of scouting networks (Mortara et al., 2010; Rohrbeck, 2010) to the establishment of document and patent mining tools (Lee \& Mortara, 2012), or the setup of calls for information via idea competitions (Mortara et al., 2013), or working with external intermediaries (Chesbrough, 2006; Jeppesen \& Lakhani, 2010). 
Intelligence provision is important to decision-making and strategy-formulating, which is why performance measurement and success factors for TI require attention (Dinter, 2013; Mortara et al., 2009). The majority of the literature on TI mentions the importance and the need to control and assess TI (Kerr et al., 2006; Mortara et al., 2009; Rohrbeck, 2007) but, so far, very few scholars have delved into the details of how this is, or should be, done. In particular, several measures of performance are available across different streams of literature, including the foresight (Battistella, 2014), the innovation management (Adams et al, 2006) or the information quality (Stvilia et al., 2007) literature, but there is not yet a consolidation of this knowledge. This work has the ambition of such a consolidation, pursued by studying directly those faced with the task of measuring TI in practice.

The structure of the literature review is as follows: the general performance measurement literature is reviewed in Section 2.1; performance measures specifically in TI are reviewed in Section 2.2; an analytical framework for measuring TI is illustrated in Section 2.3. Its purpose is to structure the findings from the literature review and act as a guide in the data collection and analysis phase.

2.1 Why should management practices be measured? Performance measurement in the management literature

Performance measures are a way of communicating top-level strategies across a company. They are also a means to quantify the efficiency and effectiveness of actions and processes (Neely et al., 2005; Flapper et al., 1996; Neely et al., 1997). For others, the fundamental function of metrics is to exercise control, communicate and improve performances (Melnyk et al., 2004). Performance measures are created, for example, when prompted by a business need, for audit purposes and to model activities, or for benchmarking reasons (Bourne \& Neely, 2003). Traditional performance measures are used to quantify the financial performances of a company (e.g. Keegan's Performance Measurement Matrix (Keegan et al., 1989)). However, metrics could also be developed to measure seemingly fuzzy processes, as demonstrated by the Quality Evaluation Framework (Heidari \& Loucopoulos, 2013). The literature describes the complexity of developing and implementing good performance measures (Neely et al., 2000; Neely, 2002; Neely, 2006).

Simons has shown that companies with different management control systems used different evaluation and reward strategies (Simons, 1990) and literature has shown that performance measures influence people's behaviour in both positive and negative ways. On one side, well- 
communicated metrics could change people's behaviour and help achieve a common business goal. However, performance measures could also encourage short-termism where people lose sight of the longer-term objectives in order to achieve good scores on short-term measurements (Neely et al., 2005). TI managers should be particularly careful and try to avoid such shortfall, because intelligence work does not usually bear immediate results or rewards (Wheaton \& Chido, 2007). Neely et al. state that the key issue in designing performance measures "is that they have to match the organisation context" (Neely et al., 1997, p.1135). Hence, the type of performance measurement to be chosen needs to link with the organisational culture. Within a clan culture an informal control strategy is most effective (Büschgens et al., 2013). On the contrary, Wynen argued that hard forms of control, which entail performance-related awards, induces higher levels of innovation-oriented culture (Wynen et al., 2014). Such control of organisations' activities could be achieved through setting standards, monitoring processes and results, which indirectly control behaviours and output, possibly with the use of metrics and indicators (Grieves, 2010). Enforcing a performance measurement system on innovative functions such as TI should be carefully considered, so that it does not interfere with innovative cultures, considering that to capture and share new knowledge requires a certain degree of openness and flexibility (Durst \& Ståhle, 2013). Besides, managers need to ensure that the goals set for the TI team fit the long-term technology strategy of the company (Melnyk et al., 2014).

\subsection{What do we know about measuring TI?}

Intelligence is essentially the gathering and dissemination of information for different purposes. Therefore, works relevant to performance measurement are found in different streams of literature. When talking about information and knowledge management evaluation, this is often done in terms of efficiency and effectiveness (Neely et al., 2005) and these criteria are adopted to evaluate information systems for foresight (Battistella, 2014).

Efficiency is substantially an evaluation of the TI process whereby, according to the foresight and IQ literature, cost, time, methodology employed, ethics and rigour feature as key metrics (Battistella, 2014). Effectiveness instead refers to the outcome of the process and the value of the results (Battistella, 2014). Across the streams of literature, the outcome is measured in different ways. It has been suggested to measure the impact of intelligence on the firms' overall knowledge which could be stored in tacit or explicit form. For the explicit part, knowledge repositories (the codified knowledge inside a database) can be evaluated in various ways (Adams et al., 2006). For the tacit part, Battistella summarises metrics such as "number of new 
networks formed" or "changing existing institutions and building partnerships among actors" under the category of "social capital and people" (Battistella, 2014).

When TI is used primarily to support innovation processes, it can be measured on its impact on the firm's innovation strategy capability (Adams et al., 2006). Hence, the results of searching for information outside can also be measured according to the innovativeness of the organisation as a consequence of using intelligence. Although metrics such as "rate of innovative product launched" have been suggested, the challenge for practitioners (e.g. the technology scouts) is that it could be difficult to link the final result, such as the revenue generation from innovative products, to a TI project (Melnyk et al., 2014). The success of innovation projects depends on other business functions, and TI knowledge could face a variety of obstacles to get to the market (Rohrbeck, 2007; Kaplan \& Tripsas, 2008). Others suggest using the "rate of ideas generated" as a result of searching outside (Chiesa et al., 1996; Salter \& Ter Wal, 2014).

The information Quality (IQ) literature concentrates instead on measuring the outcome of TI in terms of its intrinsic value - i.e. the quality of information itself. As organisations are increasingly looking at ways to measure and improve IQ within their businesses, research on IQ has increased significantly (Lee et al., 2002). Several frameworks have been proposed for IQ measurement purposes (e.g. Lee et al., 2002; Stvilia et al., 2007; Woodall et al., 2013); nevertheless, they are mostly quantitative metrics popular within the computer science literature, and are scarcely mentioned within the TI literature (with few exceptions e.g. Kerr et al., 2006). In this field, Naumann \& Rolker categorised IQ evaluation into three assessment classes (subject, object and process criteria) and developed a set of IQ metrics for each class (Naumann \& Rolker, n.d.). This aligns with the TI operating cycle: where the subjects are the intelligence practitioners and the decision-makers, the object is the TI message and the process links to the various steps of the TI cycle (identify, coordinate, search, filter, disseminate and decide) (Kerr et al., 2006). Along these lines, the metrics proposed for the intelligence messages generated by the intelligence process focus on the quality of the (competitive (West, 2001) and technology (Kerr et al., 2006)) include for instance "accuracy", “depth", "relevance", "responsiveness" and "timeliness." In addition, other IQ dimensions are "intrinsic value", "accessibility", "contextual" and "representational" value (Wang, 1998). Each category includes IQ metrics, for example, the "intrinsic information" category includes metrics such as "accuracy" or "objectivity." The literature on IQ lacks, however, an explanation on how such dimensions could be applied in the real world to assess intelligence insights developed by the overall TI systems. 


\subsection{An analytical framework for measuring TI}

[Insert Figure 1 about here]

Figure 1 presents an analytical framework summarising the works reviewed so far across the different streams of literature. Elements of performance measure (such as process and outcome) were used in the TI context. This framework was to be employed to guide the design of interview questions. The figure describes different points (and associated criteria) to measure TI:

1) The TI cycle (process) (Kerr et al., 2006). These metrics measure the TI activity;

2) The TI process outcome, i.e. the TI message. In this case the judgement is at the level of the knowledge generated and the measures proposed by the IQ literature seem relevant;

3) The ultimate use of the intelligence, i.e. decision-making process. In this case the judgement is about the impact of using TI.

The first point could be associated with the concept of efficiency; the latter two measuring points refer to the effectiveness of TI.

With this framework in mind, we set out to gain insight into current TI evaluation methods in industry, to understand the challenges associated with measuring TI in practice and to create a framework to incorporate the empirical research into theory.

\section{Research methodology}

This section describes the research methodology of this work. It starts with the methodology selection, research design and case selection. The sampling strategy for the cases is further elaborated followed by the interview design. Finally, the method of analysis is outlined.

This work used a qualitative and exploratory approach, given that there was little prior research in performance measurement in TI. The literature review was performed to establish a high level fundamental understanding of the topic, with a proposed analytical framework to structure the data analysis. Data was primarily collected through semi-structured interviews complemented by documents provided by the interviewees. We chose to engage in semistructured interviews as "interviews provide opportunities for mutual discovery, understanding, reflection and explanation [...] and elucidate subjectively lived experiences and viewpoints" (Tracy, 2013, p.132). This method is most suited for inductive empirical study (Eisenhardt \& 
Graebner, 2007). Further, a focus group was organised, with the scope to enrich the understanding of the topic through discussions with participants. The synergistic group effect in focus groups can generate a larger number of ideas through the interactions and stimulated discussions (Stewart \& Shamdasani, 1990). It is this group energy and diversity of opinions that distinguishes focus group interviews from conventional one-to-one interviews (Berg, 2001; Chiu, 2003). The data from the focus group complemented and triangulated the data collected from case studies. Hence, we employed a mixed methods research approach (Johnson \& Onwuegbuzie, 2004), where case study was chosen as a primary method, and the focus group discussion as a complementary addition to the research methodology. A nested arrangement was chosen where the focus group was nested within the case study method (Yin, 2006).

Interviewees were preferentially accessed through a research consortium, and networks, from the Centre for Technology Management (CTM), University of Cambridge. The research consortium is a collaboration between CTM and industrial partners from multinational companies in a variety of sectors. The managers participating are involved in innovation and technology management issues within their firms and range in hierarchy (from top management to operational managers). The consortium follows an engaged scholarship philosophy (Van De Ven, 2007) and aims to conduct practice-oriented research, and share experience between academia and industry. This was a pragmatic choice, guaranteeing access for direct interviews and identifying suitable interviewees. In addition, contacts were accessed through the authors' personal network. To be considered for the interview, companies should:

- Have more than 800 employees

- Carry out (technology) intelligence activities

- Operate in a technology-intensive environment

- Operate internationally

The preferred interviewees should:

- Have the role of technology managers or technology scouts

- Have more than three years of experience conducting TI

The selection of interviewees followed a theoretical sampling strategy (Patton, 1980; Glaser, 1978). This was chosen because it offers the advantage of strengthening the rigour of the cases to generate theory (Coyne, 1997). Diversity in the sample was sought as the interviewees included a number of multinational corporations operating in different industries, a research institute, a government agency and a military department in the defence sector. 
A total of 12 case study interviews and one focus group were carried out (where eight managers who were not involved in the interviews participated) (see Table 1).

[Insert Table 1 about here.]

Interviews were carried out following a semi-structured protocol whereby the main questions were set out in advance, but the interviewer was free to expand over topics of interest that emerged during the session. All interviews lasted one hour. The questions were sent to the interviewees ahead of the interview, and follow-up documents were collected after the session. Four of the 12 interviews were conducted in person, and the rest were carried out over the phone. All the interviews were recorded with the consent of the interviewees.

The interview questions were designed to cover these main sub-topics:

- What is the context for TI in your organisation? Why is it carried out?

- What kind of knowledge management system is used to store and share information/ intelligence?

- How is TI measured (e.g. explicitly or implicitly)?

- What are the challenges in trying to measure TI?

- How important it is to measure TI for you/your firm and why?

After the interviewees discussed the measures used in their companies to assess TI, they were explicitly presented with a list of IQ metrics. They were asked to discuss and elicit the IQ metrics that they considered important for TI information.

The focus group lasted 1.5 hours, and was conducted using a series of open-ended questions similar to the ones used in the interviews. The discussion was recorded. The important points were captured on post-it notes, which were rearranged in clusters during the workshop. The findings and outcomes of the discussion were summarised and presented back to the interviewees at the end of the session for validation.

For the within-case analysis, the transcriptions from the interviews were coded and organised according to patterns in the statements. We then found relationships between different codes (e.g. "activity metrics", "measure the process", and "how we go about it"). A cross-case analysis was performed to compare and contrast the results from each case. Analytic manipulation techniques were used; for instance, putting information into different structures, creating data displays and matrices, and tabulating the frequency of codes occurrence across the different 
interviews (Miles \& Huberman, 1994). To choose the important elements of the framework, we looked for reinforced agreement across the evidence. For instance, when more than half of the sample mentioned a time-related dimension such as "short-term vs long-term or "projectspecific vs non project-specific", it was decided that this factor should be incorporated in the framework. The data from the interviews were also compared to the focus group, to ensure a level of consistency in the results.

This process was repeated iteratively to construct a theoretical framework (Eisenhardt, 1989). After the framework was fixed, we placed it within the context of previous theories and research findings, and discussed its significance and limitations.

\section{Results}

Section 4.1 discusses the interviewees' opinion about the need to measure TI; Section 4.2 categorises the metrics currently used in practice under the "activity vs outcome" (Section 4.2.1) and "project vs firm" (Section 4.2.2); Section 4.3 reports the challenges associated with the metrics suggested in Section 4.2. Data from interviews are indicated as C1 to C12. FG stands for Focus Group.

\subsection{The need for TI measures}

Many interviewees expressed a need for establishing performance measures in their TI processes (e.g. C1, C3, C4, C5), whilst others rejected the notion of quantifying their work in TI (e.g. C4 and C9). One of the main reason for measuring TI is to justify the investment of resources in TI. For example, "We have to be able to demonstrate some level of value, particularly as we move into using funding and resources to bring in these technologies" (C5). $\mathrm{C} 10$ had in the past needed to prove the added value of TI when he requested resources: "We have made several attempts over the years, largely to convince the management that what we are doing is worthwhile. The most recent effort we put into monitoring quality, value and usefulness, was brought up when we needed to start recruiting... the executive board required us to produce a report to justify this. That was not the first time we have gone through an exercise trying to measure the value [of TI]... you do get people in management who think that everything is on the internet, where you can just Google [it]. We are trying to prove that in fact it is not the case." 
Interviewees who were not working in an environment governed by any formal performance measure recognised their potential use for instance to track progress, C4: "[.. ]metrics can be useful for different things; for example, understanding how valuable is being a certain intermediary you are using, what interaction are you getting with them and what is the conversion rate for things that are looking promising. It will help you know how efficient that route is. So it is not [only for] measuring the value, but almost the efficiency of what you are doing and [whether you] should be doing something different." Another reason could be to communicate their current position to the management, C10: "In general, we are not very worried about performance measurement, until one day the manager turns around and ask 'how you're doing?"'. Lastly, performance measures are seen as a way to create a structure and some level of control when the function gets larger, C8: "It's not formally monitored at the moment, if it was bigger we would start to make this more managed." and C2: "Because you still need to link back to the core business, you can't just let people search... at some point when it is growing, you have to manage and structure it."

\subsection{Metrics used}

Table 3 in the appendix presents an overview of the key metrics reported by the interviewees.

\subsubsection{Activity vs Outcome-based metrics}

Many interviewees have pointed out that for TI it would be more sensible to measure the process (the level of activity), rather than its outcome (the quality and value of the intelligence). For example, "In TI [...] measuring the results would be hard. Because it is a new technology and you don't know where to go. Maybe [we should] measure the processes" (C3).

Many $(\mathrm{C} 1, \mathrm{C} 4, \mathrm{C} 5, \mathrm{C} 7, \mathrm{C} 11, \mathrm{C} 12)$ propose the "number of leads" as a good proxy measure to demonstrate the level of TI activities. "We have the number of ideas being generated, the number of leads that exist and the number of leads that feed into the whole process of seeking" (C5). Others offered different activity metrics: "Network gained" (C2, C3, C4, C5, C6, C8, $\mathrm{C} 11)$, "speed to decision-making" (C5, C10, C11) and "geographical coverage" (C4, C5, C6, $\mathrm{C} 8$ ). There are also others who offered a set of generic items, such as "[I monitor] weekly posts and I [..] go through everything we've come across" (C8). C5: "[...] how many people are getting access, are reading our seeking materials is something we are looking at [as a metric]." 
In parallel, companies showed an interest in measuring the outcome of the TI process (as in its impact on the decision-making). For example, "We are trying to see the launches year by year, how many launches have had an OI component [i.e. partner leads brought in by the technology scout], and the sort of percentages, but that depends on different categories, and they vary year to year, so we are still learning, how that metric can tell us more about the value of the [OI activity] into each one of the categories of the turnover." Similarly, C11 evaluated TI on the basis of the value of the projects brought in (number of technology start-ups): "My individual target is to focus on certain types of projects that are classified as high value, medium value and low value. The ones that are high value are obviously what everyone is more interested in bringing in, and my targets are focused around the high value end" (C11). C10 has engaged with the intelligence customers to determine the quality of their intelligence output: "We ran surveys among our users to ask them about the quality of the database, how useful it is to them, how much project money it has earned for them. So that's looking from a user's point of view, how much value they've got out of it."

C1 acknowledged the difficulty of measuring outcomes, but remained convinced that it should be the way forward: "It is more difficult to measure TI outcomes, but in the end it makes more sense to start measuring outcomes, when you have functions [TI] that are very well established and embedded into the way of working." However, not everyone agreed: "Because whether you succeed or not [in TI] is not a rule of physics, it [the technology/project] may be too expensive, it may be technically impossible, so we are not measured on the success or outcome, we are measured on how we go about it" (C9).

For the judgment of TI's outcome, interviewees were asked to comment on the IQ dimensions that were deemed important during their TI work. Figure 2 reveals the spread of the comments received and Table 2 summarises the comments related to these dimensions.

[Insert Table 2 about here]

[Insert Figure 2 about here]

\subsubsection{Project vs Firm-based metrics}

Interviewees often discriminated between short- and long-term evaluations of TI. In most cases, their TI activities are carried out within projects (e.g. "All of our activities are project-based" (C7)). Therefore, interviewees expressed the need to assess TI within a project's point of view. 
In that case, TI needs are more immediate and short-term ("[One evaluation is about the] number of papers I read for this TI project" (C6)). However, the longer-term impact of TI on the whole business was also mentioned (e.g. "Impact on revenue" (C1)). Across the interviewees, the timeframes for TI projects varied largely, depending on the type of roles and the product/technology lifecycle (a short-term project for $\mathrm{C} 11$ is a few months while for $\mathrm{C} 2$ it is $3-5$ years).

\subsection{Challenges in measuring TI}

There was disagreement on the best way to evaluate TI between those involved. One of the main challenges is that many TI processes are not formalised or standardised enough to be measured: "This is not an entirely standardised process, so the results could depend on who you talk to" (C2). The subjectivity or the personal clout of the TI officers were mentioned as common issues $(\mathrm{C} 2, \mathrm{C} 3, \mathrm{C} 5, \mathrm{C} 6, \mathrm{C} 7, \mathrm{C} 8, \mathrm{C} 12)$. For example: "When you are established... people will listen to you, if you are not then it is very difficult" (C6).

Interviewees pointed out that performing well in activity metrics does not always guarantee a good TI outcome: "It is not entirely appropriate to use activity metrics as a representation of value creation" (C4). The opposite was also mentioned, because "it is not fair to assess scouts purely on value creation metrics, because it takes too long for things to go through the pipeline and there are so many other factors that are going to influence what happens to it" (C4).

It is important for managers to monitor both short- and long-term performances simultaneously and maintain a portfolio of perspectives in TI. In the interviews, they reported a tendency towards focusing on the immediate project needs and the risk of losing sight of the longer-term implications. For instance: "The obvious problems we have with [TI] is when someone tells us 'this [project] is a problem', then we give them priority, spend a lot of time investigating it and in the end [the result is that] there's not enough to make this [project] worthwhile" (C1). Shorttermism and the risks of formalising the metrics came up also during the interview with C9: "Tell me how you measure me and I will tell you how I behave." The concern for putting metrics in TI is that people will "work to the number and not the spirit of the idea behind the number" (C9) especially when it is linked to performance reviews and remunerations.

Focusing too much on the opposite (long-term view, informal) could also harm the TI function, as mentioned by $\mathrm{C} 4$, whose $\mathrm{TI}$ function was discontinued when the company suffered from financial issues: "[...] so you want a balance across [the spectrum], a portfolio of long-term to 
short-term things. [..] In hindsight we probably had too many long-term things and not enough short-term things, to be a proof of the value."

Finally, measuring TI is hard because it is "trying to prove the counter-factual" (C2). In some cases "you cannot justify [a TI activity] unless you implement it, and see the gap of having it or not [having it]" (C2). In response to this problem, some firms (e.g. C10) tried to implement a customer satisfaction survey to demonstrate more directly the value of TI in financial terms.

With the exception of $\mathrm{C} 2$ and $\mathrm{C} 10$ (who rely on sophisticated infrastructure for knowledge management), comments were received relating to relying on an informal, network-based mechanism to identify the internal TI knowledge: "One of the challenges that we have is "how do we pull out the information from people? Who are the people with access to a worldwide forum? Who goes to international conferences all the time?" " (C7). In most cases, some form of knowledge management system or IT tool existed, but they still relied on personal networks to track down information within the firm $(\mathrm{C} 3, \mathrm{C} 4, \mathrm{C} 5, \mathrm{C} 6, \mathrm{C} 8, \mathrm{C} 9, \mathrm{C} 12)$. "[the knowledge management system] is very people-based, not system-based. There is no single page I could go to, to find information on what has been done before or when. [To know] what work has been done, I have to know the people and go and talk to them.", C9. C12 agrees: "We have lots of lessons learnt. I don't think we tap into them. We have lots of pressure to commit to timescales, so I think sometimes we over-commit and under-deliver. It is about trying to get the correct balance. And that's the thing, it is about how do you get the best of out these systems and how do you share things between stakeholders. We don't analyse enough why some things don't work and use that as a mechanism to improve."

\section{Discussion}

The main objective of this paper is to gain insights on current assessment practices in TI, and to develop a framework to support TI evaluation. To this end, we have extracted from interview data formal and informal measures of TI currently used in industry. This section analyses the results and discusses the implications. Starting with the analysis for the need for measuring TI, this section discusses the pros and cons of the metrics used, and summarises them in a framework. 
Although respondents were sometimes not completely convinced of the needs for TI metrics, we have noticed that, in practice, TI performances were measured and evaluated both explicitly or implicitly, and this was in alignment with what illustrated in literature (Neely, 2002).

Consistent with what described in the literature (see Figure 1)(e.g. Wheaton \& Chido, 2007), we also observed that practitioners separated metrics into activity- and outcome-based. Activity metrics were used to communicate the level of activity within the TI function, and as an indicator of the efforts and progress of the TI process. In this case, the knowledge management processes, idea generation process, the knowledge repository or the information flow (Adams et al., 2006) were the objects of assessment. For the outcome metrics, against what suggested in literature (Kerr et al., 2006), with the exception of those who dealt with computerised knowledge repositories and information systems (e.g. C10), we did not find that managers evaluate the specific insight - the outcome of the TI process. This was in contrast with practitioners' desire for a clear distinction so that the value of TI would not be unfairly judged by what appears to be the outcome of the decision. When specifically asked to comment on a list of IQ metrics, they had a variable interpretation of the meaning of each metric. "Credibility" was a particularly subjective metric, dependent on the culture of the organisation and the characteristics of the recipients of the message. West proposed to measure competitive intelligence (CI) with "accuracy", "depth", "relevance", "responsiveness", "timing" and "comprehensiveness" (West, 2001). However, "relevance", "credibility" and "accessibility" were indicated as important by TI officers and only "relevance" matches the CI evaluation criteria. "Timeliness", which was also mentioned by the foresight literature (Battistella, 2014), was considered less important. None of the interviewees chose "completeness" as an important metric in TI. This perhaps was due to the different nature of TI and CI: in CI there is a higher possibility of obtaining comprehensive information about the competitors, but it is much harder to obtain a complete picture of emerging technologies worldwide. Another IQ metric which seems to be highly subjective, and dependent on the culture, is "verifiability", as the comments received showed that some interviewees meant the verifiability of the source of information, whilst others meant how believable that information is for the decision-maker.

In many other cases, TI was evaluated on the basis of the consequences of its uses, such as the innovativeness and well-being of the firm, or the success and value of some specific projects (i.e. based on the outcome resulting from the use of the intelligence message). This reflects the innovation management metrics (Adams et al., 2006). 
Besides that, the evaluation of TI was done in relation to a specific context, which could be either project- or firm-specific. Project-specific metrics are generally non-reusable in the wider or longer-term context. Firm-specific metrics are not bound to any single project, and are a means for indicating the effectiveness, efficiency and sustainability of the TI function in the longer-term. Most of our interviewees conducted intelligence by projects (Adams et al., 2006), whilst some (e.g. C1) focused on the holistic contribution of TI to the organisation (Chenhall \& Langfield-Smith, 2007).

According to the observations above, the metrics used in practice could be placed on a framework matrix (see Figure 3), where each quadrant is described below.

\subsection{TI Evaluation Matrix}

[Insert Figure 3 about here]

\subsubsection{Activity-based \& Project-specific}

These metrics are the easiest to measure and quantify. This is the area least affected by personal biases. Metrics such as "the number of leads gained" and "the number of papers/patents reviewed" are easily quantifiable and bear a certain level of objectivity. Nevertheless, the challenge here is that the level of activity does not necessarily lead to the quality of the TI outcomes (C3 and C4). These metrics can be useful for TI activities that take a long time, and where there is the risk of providing interim and partial results of an investigation, which might bias the decision-makers, as they could unduly provide a point of anchoring (Mortara, 2015).

\subsubsection{Activity-based \& Firm-specific}

The metrics here are used to monitor the level of progress and activity and the health of the TI system and processes. Both "geographical coverage" and "network gained" are popular means of measuring the health of the company's TI function. Nevertheless, interviewees mentioned indicative measures that they did not routinely capture and quantify. According to Neely et al., informal, verbal and perceived measures are the foundations for designing performance measures that fit the requirements of the organisation (Neely et al., 2005). Hence, these metrics could be fundamental to evaluate the health of the TI activity and system within the firm, and implicit or informal measures can be used to check position, communicate position, confirm priorities or to compel progress - based on Neely's four "CP's" of measurement (Neely, 2006).

\subsubsection{Outcome-based \& Project-specific}


Metrics in this quadrant are usually employed after a project is completed, and are used to evaluate its results. Recent research (Salter \& Ter Wal, 2014) indicates that, with the increase of external searches, the number of ideas taken up in specific projects rises up to a point, after which the costs of managing too many inputs overcomes the advantages of receiving them. However, the results of a TI project could be influenced by many factors beyond the validity of the intelligence received (such as budget constraints or lack of supporting infrastructure to develop the project ( $\mathrm{C} 4$ and $\mathrm{C} 9)$ ), and hence these measures can be inadequate, if used in isolation, to determine the performance of TI.

\subsubsection{Outcome-based \& Firm-specific}

This quadrant is important for measuring the effectiveness of TI for a company in the longer term. Ultimately, indicators in this quadrant are what the companies want to achieve with their technology strategy. However, very few companies in our sample explicitly measured TI in this quadrant. Managers usually get a "sense" or "feel" about how well the TI is delivering value (C8), and the criteria they used may be only implicitly based in this quadrant. Measuring in this quadrant could be opinion-based, subjective, and down to interpretation $(\mathrm{C} 2, \mathrm{C} 3, \mathrm{C} 5, \mathrm{C} 7, \mathrm{C} 8$, C9, FG). Also, losing control of the short-term benefit of the TI activity in the day-to-day routine can ultimately undermine its importance in the eyes of top management (C4). In TI, it is often hard to determine the results $(\mathrm{C} 3, \mathrm{C} 4, \mathrm{C} 9)$, because "it takes too long for things to go through the pipeline and there are so many other factors that are going to influence what happens to it" (C4). For this type of evaluation, data needs to be collected over a long period (it is very difficult for practitioners to demonstrate and correlate TI performance with the wealth of an organisation, as it takes a long time for any TI message to underpin any company wealth) and people and processes could have changed (Mortara et al., 2009). Some researchers propose that search activities are carried out only by successful organisations, which have the availability of financial slack (O'Brien, 2003), and hence measuring TI success by linking it with the company's financial success might be a tautology.

\subsection{Theoretical and practical implications}

The research gap we are addressing is the lack of empirical research into how organisations actually evaluate TI. Both Enkel et al. and Durst \& Ståhle listed "use of explicit performance measure" as a criterion of a mature Open Innovation (OI) system (Enkel et al., 2011; Durst \& Ståhle, 2013). This should also apply to other routines underpinning OI, such as TI. We believe that the framework we have presented here contributes significantly to TI theory by collecting and structuring the fragmented data of TI metrics currently used in practice, and comparing it with the understanding found in various streams of literature. For practitioners, the advantages 
of having a matrix of this sort are to contextualise their performance, to encourage practitioners to adopt more than one metric, and to draw attention to the limitations of some of the current evaluation practices.

Many works can be found in the literature that support the structure of the framework derived here, in particular in activity/process vs outcome metrics. Drawing references from the organisational culture and innovation literature, Ouchi's model supported the TI Evaluation Matrix by distinguishing behaviour (or activity-based) and output (or outcome-based) measurement (Ouchi, 1979). Like others (Wheaton \& Chido, 2007; Neely et al., 2005), we showed that intelligence, like any other routine, could be done from a process or a product point-of-view.

However, the strength of the TI Evaluation Matrix is that it adds an extra dimension to the contextualisation of the assessment (the short-term/project focus vs the long-term/firm focus). This allows an organisation to plot its measures, and to identify the need to adjust measurement focus (Kennerley \& Neely, 2004), which is particularly important as the metrics have such a subjective meaning, as demonstrated above. The framework reflects the innovation management literature, suggesting that evaluating an innovation or technology management activity needs to be done across the processes of knowledge and innovation strategy - as indicated by Adams et al. (2006). The TI Evaluation Matrix shows links to the concept of effectiveness (outcome) and efficiency (activity) of foresight systems (Battistella, 2014). However, in contrast with Battistella, we showed that the measures listed by industry fall into a more complex set of categories. The evidence we collected shows that the evaluation of TI is subjected to the purpose and the role that TI serves within the organisation. Some interviewees had more strategic intents, whilst others, in particular the OI managers, focused primarily on identifying leads to fit with current innovation pipelines, showing that OI is often carried out for exploitative reasons (March, 1991). This makes the timeframe for the evaluation different (long-term impact and evaluation for the first, and short-term focused on projects for the latter). TI metrics need to be relevant to the stakeholders directly involved in the TI process, such as technology scouts and their respective intelligence consumers, whereas holistic innovation measures are more of interest to top level management and shareholders (Dewangan \& Godse, 2014). As expected, TI practitioners who are mainly focused on technology scouting (C3, C5 and C6) use activity metrics (e.g. "number of leads" and "number of papers reviewed"), while those involved in strategic decision-making $(\mathrm{C} 1, \mathrm{C} 2, \mathrm{C} 9)$ are mainly concerned with the outcome of the TI process, as well as the longer-term firm-specific measures (e.g. contribution to revenue). $\mathrm{C} 3$ and $\mathrm{C} 5$ could be using project-specific activity metrics more frequently, because 
they operate in a hierarchical culture with clear reporting structures (Nobel \& Birkinshaw, 1998). The project-specific activity metrics would therefore be more relevant to them in order to quantify the work and to report their progress to managers.

\section{Conclusions}

This work has developed a framework for the evaluation of Technology Intelligence (TI) based on empirical data. The TI Evaluation Matrix, proposed here, can particularly help practitioners structure their measuring and evaluating strategy in TI. As most interviewees expressed the need for an organised procedure to assess their TI function, this framework serves as a tool for them to map out the metrics used, and to understand the challenges and implications within each category of metrics.

Consistent with past research on metrics, the vertical axis of the TI Evaluation Matrix distinguishes between activity and impact measures. The horizontal axis of the matrix emerges from the case study interviews, and the focus group study, indicating that a separation between project (short-term) and non-project (long-term) assessment is required. Different limitations for measuring TI exist within each category. The analysis shows that, with the exception of TI managers concerned with explicit sources of information (such as patents or journals), in practice TI is seldom measured at the level of the TI message. This contrasts with what is advocated by the information quality literature, and by some TI researchers (e.g. Kerr et al., 2006).

The four categories of metrics are not mutually exclusive and are independent from each other. It could be argued that a higher level of activity within the TI cycle can contribute to a better outcome and more value to the decision-maker. On the other hand, we should be aware that quality of method does not ensure success, which is true in both foresight and TI (Georghiou \& Keenan, 2006; Wheaton \& Chido, 2007). The demonstration of the long-term benefits of having a TI system seems to be left to researchers and industry is currently weaker in this evaluation.

Although steps were taken to ensure that this research is reliable and accurate, there are limitations to this study. We are aware of the risks in generalising a limited number of case studies. Furthermore, since data collection was carried out in the UK, our results could be biased towards a Western perspective of organisational culture, TI and performance measures (Lok \& Crawford, 2004). 
The case studies were based on relatively large global organisations, with employee numbers ranging from 800 to 274,000 . Therefore, it is not surprising that the interviewees felt there is a high need for TI performance measures because large organisations often seek to standardise and quantify their processes. This situation might be different for SMEs.

Future research should aim to:

- Strengthen the model by gathering input from both the decision-maker and the intelligence provider. The model could be studied in the context of organisational culture, for instance appreciative or regulative culture (Vickers, 1963).

- Deepen the investigation into how information quality metrics could be better understood and used for TI evaluation. This could improve the understanding of where TI systems work well, independently of the rest of the firms' absorptive capacity.

- Investigate whether there is any relationship between the level of maturity of TI in a firm and how their TI evaluation maps out in the framework.

- Adopt an action research methodology, by applying the framework in practice, and learning from successive rounds of its application (Coughlan \& Coghlan, 2002). We believe this methodology is suitable to refine the current framework because it "brings together action and reflection, theory and practice, in participation with others, in the pursuit of practical solutions to issues of [...] concern to people" (Reason \& Bradbury, 2001, p.1).

\section{Acknowledgements}

The authors would like to thank all the companies and individuals who contributed to this research. Special thanks should go to the Strategic Technology Innovation Management (STIM) Consortium for providing a platform to conduct this research. This work was done as part of a Masters dissertation for MPhil in Industrial Systems, Manufacture and Management (ISMM) at the University of Cambridge, and we are very grateful to those who offered help throughout the duration of the course.

\section{Appendix}

[Insert Table 3 about here] 


\section{References}

Adams, R., Bessant, J. and Phelps, R. (2006) „Innovation management measurement: a

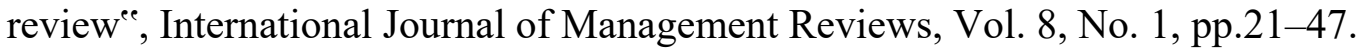

Battistella, C. (2014) „The organisation of corporate foresight: a multiple case study in the telecommunication industry ${ }^{e e}$, Technological Forecasting and Social Change, Vol. 87, pp.60-79.

Berg, B.L. (2001) Qualitative Research Methods for the Social Sciences, 4th ed., Allyn \& Bacon, Boston.

Bourne, M. and Neely, A. (2003) „Implementing performance measurement systems: a literature reviewe, International Journal of Business Performance Management, Vol. 5, No. 1, pp.1-24.

Büschgens, T., Bausch, A. and Balkin, D.B. (2013) „Organizational culture and innovation: a meta analytic reviewee, Journal of Product Innovation Management, Vol. 30, No. 4, pp.763-781.

Chenhall, R.H. and Langfield-Smith, K. (2007) „Multiple perspectives of performance measures ${ }^{\text {ee }}$ European Management Journal, Vol. 25, No. 4, pp.266-282.

Chesbrough, H. (2004) „Managing open innovation“, Research Technology Management, Vol. 47, No. 1, pp.23-26.

Chesbrough, H. (2006) Open Business Models: How to thrive in the Open Innovation Landscape, Harvard Business School Press, Boston, MA.

Chiesa, V., Coughlan, P. and Voss, C.A. (1996), „Development of a technical innovation auditee $^{\text {, }}$ Journal of Product Innovation Management, Vol. 13, No. 2, pp.105-136.

Chiu, L.F. (2003) „Transformational potential of focus group practice in participatory action research $^{e e}$, Action Research, Vol. 1, No. 2, pp.165-183.

Coughlan, P. and Coghlan, D. (2002) „Action research for operations management ${ }^{e e}$, International Journal of Operations \& Production Management, Vol. 22, No. 2, pp.220240 .

Coyne, I.T. (1997) „Sampling in qualitative research. Purposeful and theoretical sampling; merging or clear boundaries? ?e $^{\text {, }}$ Journal of advanced nursing, Vol. 26, No. 3, pp.623-630.

Davison, L. (2001) „Measuring competitive intelligence effectiveness: insights from the advertising industrye, Competitive Intelligence Review, Vol. 12, No. 4, pp.25-38.

Dewangan, V. and Godse, M. (2014) „Towards a holistic enterprise innovation performance 
measurement system ${ }^{e e}$, Technovation, Vol. 34, No. 9, pp.536-545.

Dinter, B. (2013) „Success factors for information logistics strategy - an empirical investigation ${ }^{e e}$, Decision Support Systems, Vol. 54, No. 3, pp.1207-1218.

Durst, S. and Ståhle, P. (2013) „Success factors of open innovation - a literature review“, International Journal of Business Research and Management (IJBRM), Vol. 4, No. 4, pp.111-131.

Eisenhardt, K.M. (1989) „Building theories from case study research", Academy of Management Review, Vol. 14, No. 4, pp.532-550.

Eisenhardt, K.M. and Graebner, M.E. (2007), ,Theory building from cases : opportunities and challenges $^{\mathrm{ee}}$, Academy of Management Journal, Vol. 50, No. 1, pp.25-32.

Enkel, E., Bell, J. and Hogenkamp, H. (2011) „Open innovation maturity framework ${ }^{\text {ee }}$ International Journal of Innovation Management, Vol. 15, pp.1161-1189.

Flapper, S.D.P., Fortuin, L. and Stoop, P.P.M. (1996) „Towards consistent performance management systems ${ }^{\text {ee }}$, International Journal of Operations \& Production Management, Vol. 16, No. 7, pp.27-37.

Georghiou, L. and Keenan, M. (2006) „Evaluation of national foresight activities: assessing rationale, process and impacte ${ }^{e e}$ Technological Forecasting \& Social Change, Vol. 73, No. 7, pp.761-777.

Glaser, B.G. (1978) Theoretical Sensitivity: Advances in the Methodology of Grounded Theory, Sociology Press, Mill Valley, California.

Grieves, J. (2010) Organizational Change: Themes and Issues, Oxford University Press, New York.

Heidari, F. and Loucopoulos, P. (2014) „Quality evaluation framework (QEF): modeling and evaluating quality of business processes ${ }^{\text {ee }}$, International Journal of Accounting Information Systems, Vol. 15, pp.193-223.

Huizingh, E.K.R.E. (2011) „Open innovation: State of the art and future perspectives ${ }^{\text {ee }}$ Technovation, Vol. 31, No. 1, pp.2-9.

Jeppesen, L.B. and Lakhani, K.R. (2010) „Marginality and problem-solving effectiveness in broadcast searche, Organization Science, Vol. 21, No. 5, pp.1016-1033.

Johnson, R.B. and Onwuegbuzie, A.J. (2004) „Mixed methods research: a research paradigm whose time has come ${ }^{e e}$, Educational Researcher, Vol. 33, No. 7, pp.14-26.

Kaplan, S. and Tripsas, M. (2008) „Thinking about technology: applying a cognitive lens to 
technical changee, Research Policy, Vol. 37, No. 5, pp.790-805.

Keegan, D.P., Eiler, R.G. and Charles, R.J. (1989) „Are your performance measures obsolete? ${ }^{\text {ee }}$, Management Accounting, Vol. 70, No. 12, pp.45-50.

Kennerley, M. and Neely, A. (2004) „Performance measurement frameworks - a review“, Business Performance Measurement, Cambridge University Press, Cambridge, pp.145155.

Kerr, C.I.V., Mortara, L., Phaal, R. and Probert, D.R. (2006) „A conceptual model for technology intelligence ${ }^{e e}$, International Journal of Technology Intelligence and Planning, Vol. 2, No. 1, p.73.

Lee, S. and Mortara, L. (2012) „Analysis of document-mining techniques and tools for technology intelligence: Discovering knowledge from technical documents ${ }^{\text {ee }}$, International Journal of Technology Management, Vol. 60, Nos. 1-2, pp.130-156.

Lee, Y.W., Strong, D.M., Kahn, B.K. and Wang, R.Y. (2002) „AIMQ: a methodology for information quality assessment ${ }^{\text {ee }}$ Information \& Management, Vol. 40, No. 2, pp.133146.

Lichtenthaler, E. (2004a) „Technological change and the technology intelligence process: a case studye, Journal of Engineering and Technology Management, Vol. 21, No. 4, pp.331-348.

Lichtenthaler, E. (2004b) „Technology Intelligence processes in leading European and North American multinationalse $^{\mathrm{ee}}$, R\&D Management, Vol. 34, No. 2, pp.121-135.

Lok, P. and Crawford, J. (2004) „,The effect of organisational culture and leadership style on job satisfaction and organisational commitment: a cross-national comparison ${ }^{\text {ee }}$, Journal of Management Development, Vol. 23, No. 4, pp.321-338.

Lönnqvist, A. and Pirttimäki, V. (2006) „The measurement of business intelligencee, Information Systems Management, Vol. 23, No. 1, pp.32-40.

March, J.G. (1991) „Exploration and exploitation in organizational learninge, Institute for Operations Research and the Management Science, Vol. 2, No. 1, pp.71-87. How to measure technology intelligence? 21

Melnyk, S.A., Bititci, U., Platts, K., Tobias, J. and Andersen, B. (2014) „Is performance measurement and management fit for the future? $?^{e e}$, Management Accounting Research, Vol. 25, No. 2, pp.173-186.

Melnyk, S.A., Stewart, D.M. and Swink, M. (2004) „Metrics and performance measurement 
in operations management: dealing with the metrics maze ${ }^{e e}$, Journal of Operations Management, Vol. 22, No. 3, pp.209-218.

Miles, M.B. and Huberman, A.M. (1994) Qualitative Data Analysis: An Expanded Sourcebook, Sage Publications, Thousand Oaks, CA.

Mortara, L. (2015) Communicating intelligence, U. o. C. Institute for Manufacturing, Cambridge.

Mortara, L., Kerr, C.I.V., Phaal, R. and Probert, D.R. (2009) „Technology intelligence practice in UK technology-based companies ${ }^{\text {ee }}$, International Journal of Technology Management, Vol. 48, No. 1, p.115.

Mortara, L., Thomson, R., Moore, C., Armara, K., Kerr, C.I.V., Phaal, R. and Probert, D.R. (2010)

„Developing a technology intelligence strategy at Kodak European research: scan \& target Research - Technology Management, Vol. 53, No. 4, pp.27-38.

Mortara, L., Ford, S.J. and Jaeger, M. (2013) „Idea Competitions under scrutiny: acquisition, intelligence or public relations mechanism?'e , Technological Forecasting and Social Change, Vol. 80, No. 8, pp.1563-1578.

Naumann, F. and Rolker, C. (n.d.) Assessment Methods for Information Quality Criteria [Online], Available from:

http://citeseerx.ist.psu.edu/viewdoc/download?doi=10.1.1.38.6523\&rep=rep1 \&type=pdf (Accessed 22 June, 2014).

Neely, A. (2002) Business Performance Measurement: Theory and Practice, Cambridge University Press, Cambridge, UK.

Neely, A. (2006) Measuring Business Performance - Why, What and How, The Economist and Profile Books Limited, London.

Neely, A., Richards, H., Mills, J., Platts, K. and Bourne, M. (1997) „Designing performance measures: a structured approach ${ }^{\text {ee }}$, International Journal of Operations \& Production Management, Vol. 17, No. 11, pp.1131-1152.

Neely, A., Mills, J., Platts, K. and Kennerley, M. (2000) „Performance measurement system design: developing and testing a process-based approach ${ }^{\text {ee }}$, International Journal of Operations \& Production Management, Vol. 20, No. 10, pp.1119-1145.

Neely, A., Gregory, M. and Platts, K. (2005) „Performance measurement system design: a literature review and research agenda ${ }^{e e}$, International Journal of Operations \& Production 
Management, Vol. 25, No. 12, pp.1228-1263.

Negash, S. and Gray, P. (2008) „Business intelligence ${ }^{e e}$, International Handbooks Information System, Springer Berlin Heidelberg, Berlin, Heidelberg, pp.175-193.

Nobel, R. and Birkinshaw, J. (1998) „Innovation in multinational corporations: control and communication patterns in international R\&D operations ${ }^{\text {ee }}$, Strategic Management Journal, Vol. 19, No. 5, pp.479-496.

O'Brien, J.P. (2003) „The capital structure implications of pursuing a strategy of innovation Strategic Management Journal, Vol. 24, No. 5, pp.415-431.

Ouchi, W.G. (1979) „A conceptual framework for the design of organisational control mechanisms ${ }^{\text {ee }}$, Management Science, Vol. 25, No. 9, pp.833-848.

Patton, M.Q. (1980) Qualitative Evaluation Methods, Sage Publications, Newbury Park, CA.

Prescott, J. (1999) „The evolution of competitive intelligence ${ }^{e e}$, Proposal Management, Vol. 6, pp.71-90.

Reason, P. and Bradbury, H. (2001) Handbook of Action Research: Participative Inquiry and Practice, Sage Publications Ltd., London.

Reger, G. (2001) „Technology foresight in companies: from an indicator to a network and process perspective ${ }^{\text {ee }}$ Technology Analysis \& Strategic Management, Vol. 13, No. 4, pp.533-553.

Rogo, F., Cricelli, L. and Grimaldi, M. (2014), Assessing the performance of open innovation practices: a case study of a community of innovation"e, Technology in Society, Vol. 38, pp.60-80.

Rohrbeck, R. (2007) „Technology scouting a case study on the Deutsche Telekom Laboratories $^{\text {ee }}$ ISPIM-Asia, 9-12 January, 2007, New Delhi, India, pp.1-14.

Rohrbeck, R. (2010) „Harnessing a network of experts for competitive advantage: technology scouting in the ICT industry ${ }^{\mathrm{ee}}$, R \& D Management, Vol. 40, No. 2, pp.169-180.

Salter, A. and Ter Wal, A.L.J. (2014) „Open for ideation: individual-level openness and idea generation in R and Dee, Journal of Product Innovation Management, Vol. 32, No. 4, pp.1-17.

Simons, R. (1990) „The role of management control systems in creating competitive advantage: new perspectives ${ }^{e e}$, Accounting, Organizations and Society, Vol. 15, No. 112, pp.127-143.

Stewart, D.W. and Shamdasani, P.M. (1990) Focus groups: Theory and practice, Sage, 
Newbury Park, CA.

Stvilia, B., Gasser, L., Twidale, M. and Smith, L. (2007) „A framework for information quality assessment ${ }^{\mathrm{e}}$, Journal of the American Society for Information Science and Technology, Vol. 58, No. 12, pp.1720-1733.

Tracy, S.J. (2013) Qualitative Research Methods: Collecting Evidence, Wiley-Blackwell, Chichester.

Van De Ven, A.H. (2007) Engaged Scholarship - A Guide for Organizational and Social Research,Oxford University Press, Oxford.

Vickers, G. (1963) „Appreciative behaviour ${ }^{\text {ee }}$ Acta Psychologica, Vol. 21, pp.274-293.

Wang, R.Y. (1998) „A product perspective on total data quality management

Communications of the ACM, Vol. 41, No. 2, pp.58-65.

West, C. (2001) Competitive Intelligence, Palgrave Macmillan.

Wheaton, K.J. and Chido, D. (2007) „Evaluating intelligence ${ }^{e e}$, Competitive Intelligence Magazine, Vol. 10, No. 5, pp.19-23.

Woodall, P., Borek, A. and Parlikad, A.K. (2013),„Data quality assessment: the hybrid approach $^{\text {ee }}$ Information \& Management, Vol. 50, No. 7, pp.369-382.

Wynen, J., Verhoest, K., van Thiel, S. and Ongaro, E. (2014) „Innovation-oriented culture in the public sector: Do managerial autonomy and result control lead to innovation?"e Public Management Review, Vol. 16, No. 1, pp.45-66.

Yin, R.K. (2006) „Mixed methods research: Are the methods genuinely integrated or merely parallel? ${ }^{\text {ee }}$, Research in the Schools, Vol. 13, No. 1, pp.41-47. 
Y. W. Loh, L. Mortara

Figures and Tables:

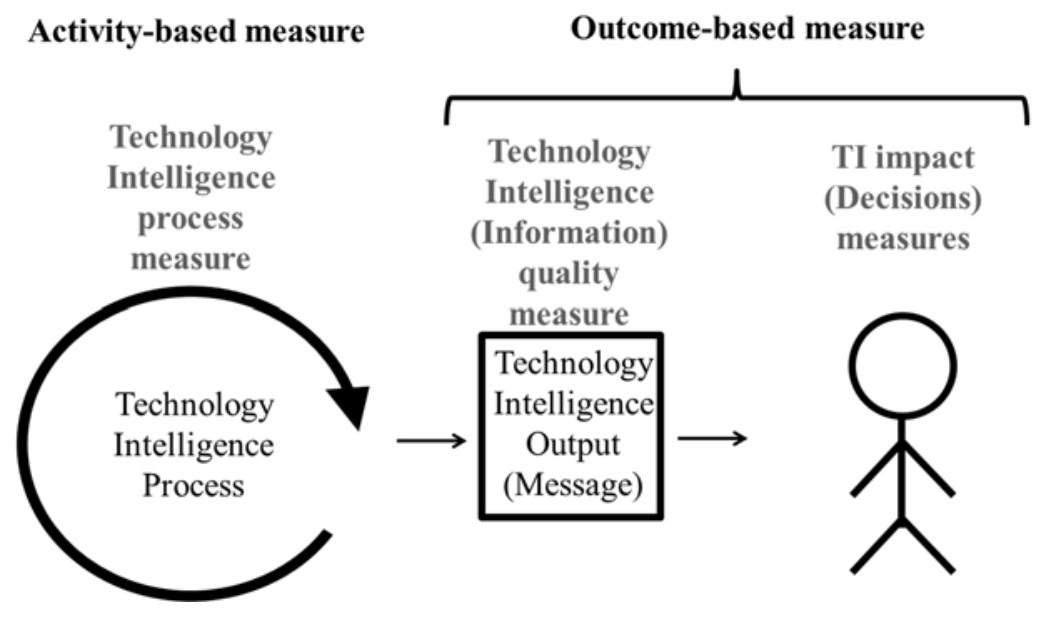

Figure 1: Different points of evaluation of technology intelligence 
How to Measure Technology Intelligence?

\section{Frequency of the dimensions being selected}

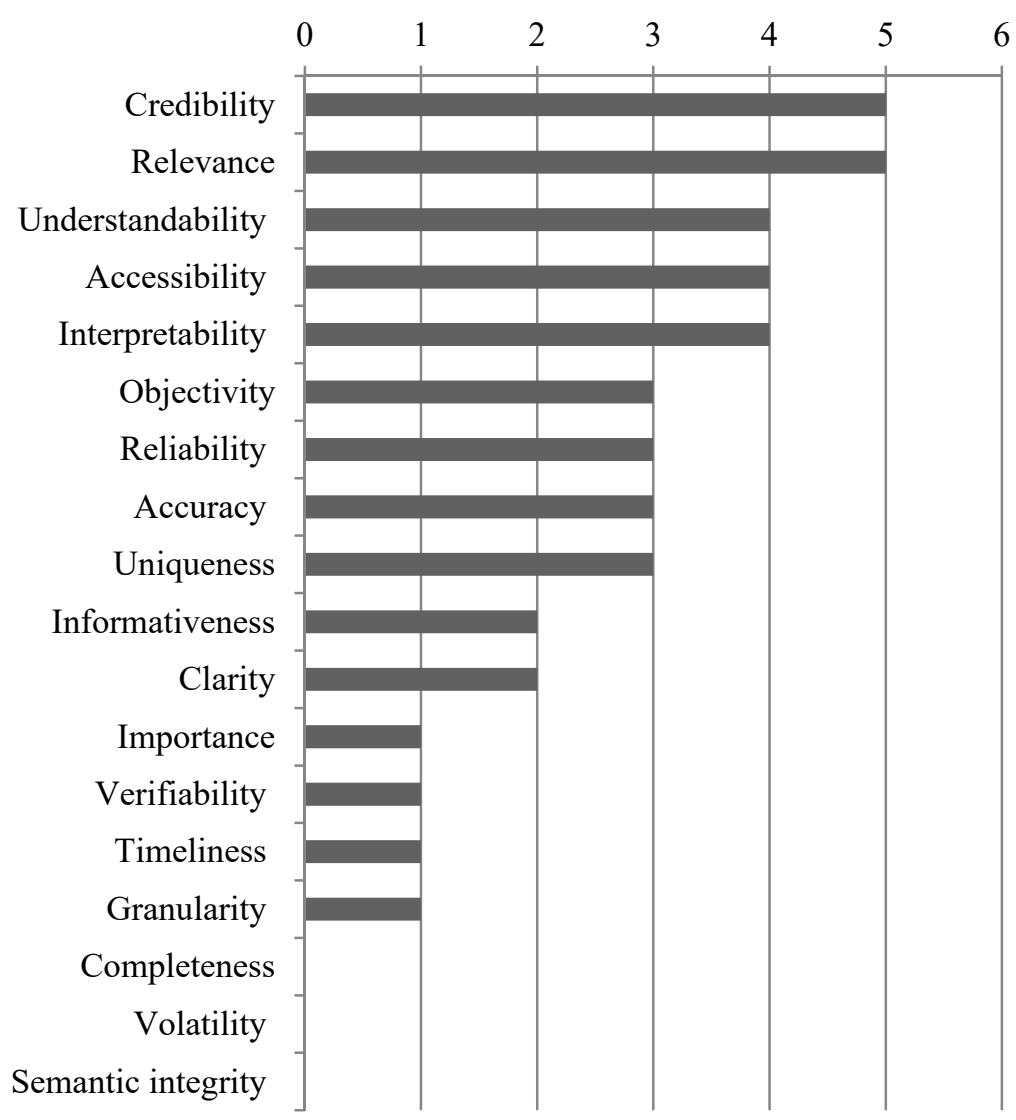

Figure 2: Information quality metrics results 

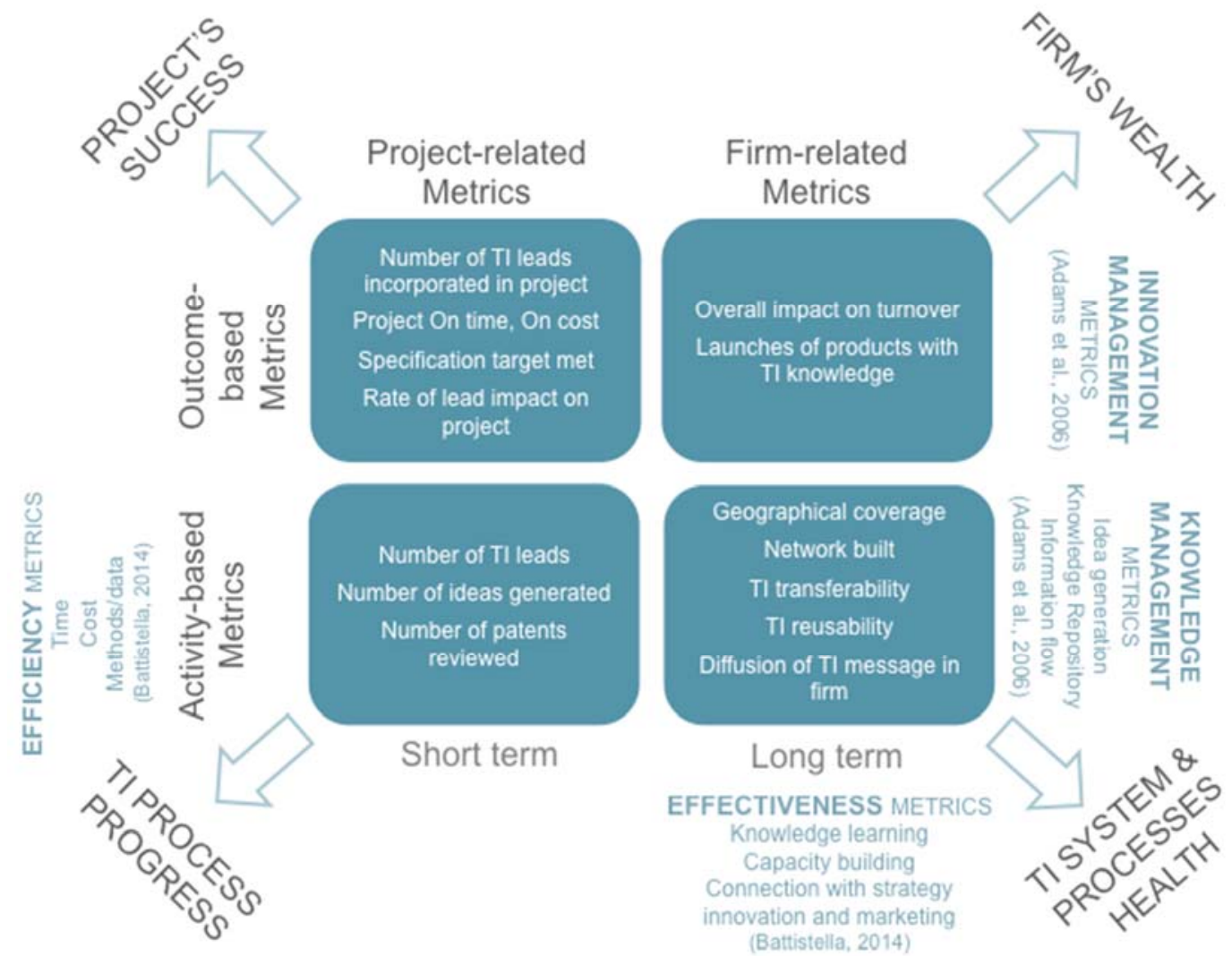

Figure 3: TI evaluation matrix 


\begin{tabular}{|c|c|c|c|c|}
\hline Case & Sector/company & $\begin{array}{l}\text { Total } \\
\text { employees }\end{array}$ & Interviewee's role & Department \\
\hline 1 & $\begin{array}{l}\text { Fast-moving } \\
\text { consumer goods }\end{array}$ & 174,000 & $\begin{array}{l}\text { Open innovation } \\
\text { manager }\end{array}$ & R\&D \\
\hline 2 & Oil and energy & 83,900 & Strategy advisor & Group technology \\
\hline 3 & $\begin{array}{l}\text { Home appliances } \\
\text { manufacturer }\end{array}$ & 23,400 & $\begin{array}{l}\text { Team leader - } \\
\text { Structural design \& } \\
\text { prototype }\end{array}$ & $\begin{array}{l}\text { Structural design } \\
\text { department }\end{array}$ \\
\hline 4 & $\begin{array}{l}\text { Technology company } \\
1\end{array}$ & 8,800 & $\begin{array}{l}\text { Head of innovation } \\
\text { (previous) }\end{array}$ & $\begin{array}{l}\text { European research } \\
\text { group }\end{array}$ \\
\hline 5 & Pharmaceutical & 99,000 & Seeker & $\begin{array}{l}\text { Advanced } \\
\text { manufacturing } \\
\text { technology R\&D }\end{array}$ \\
\hline 6 & Defence department & NA & Staff officer & Planning branch \\
\hline 7 & Research institute & 800 & $\begin{array}{l}\text { European funding } \\
\text { coordinator }\end{array}$ & $\begin{array}{l}\text { Joining technologies } \\
\text { department }\end{array}$ \\
\hline 8 & $\begin{array}{l}\text { Technology company } \\
2\end{array}$ & 4,000 & $\begin{array}{l}\text { External research } \\
\text { programme manager }\end{array}$ & $\begin{array}{l}\text { Research, design \& } \\
\text { development }\end{array}$ \\
\hline 9 & $\begin{array}{l}\text { Fast-moving } \\
\text { consumer goods }\end{array}$ & 274,000 & $\begin{array}{l}\text { Technology } \\
\text { innovation manager }\end{array}$ & $\mathrm{R} \& \mathrm{D}$ \\
\hline 10 & $\begin{array}{l}\text { Technology company } \\
2\end{array}$ & 800 & $\begin{array}{l}\text { Software system } \\
\text { manager }\end{array}$ & Library \\
\hline 11 & $\begin{array}{l}\text { Trade and investment } \\
\text { agency }\end{array}$ & 2,300 & Technology specialist & Information services \\
\hline 12 & Aerospace company & 54,100 & $\begin{array}{l}\text { Assembly commodity } \\
\text { strategy lead }\end{array}$ & Capability acquisition \\
\hline
\end{tabular}

Table 1: Description of case study interviewees and their role 


\begin{tabular}{|c|c|c|}
\hline IQ Dimensions & Cases & Comments \\
\hline \multirow[t]{4}{*}{ Credibility } & 1 & $\begin{array}{l}\text { "Certain academic circles will lower the credibility of information } \\
\text { you receive because they are not coming from people with a scientific } \\
\text { background." }\end{array}$ \\
\hline & 3 & $\begin{array}{l}\text { "Credibility is important in the beginning, to make people listen to } \\
\text { you." }\end{array}$ \\
\hline & 11 & "We look for track records.” \\
\hline & FG & $\begin{array}{l}\text { "Credibility of the TI messenger comes from his/her experience in } \\
\text { the market or technical area." }\end{array}$ \\
\hline Relevance & 7 & $\begin{array}{l}\text { "It is [about] how relevant it is to the project, the goals of the project } \\
\text { or application or decision, and is usually important but not well done } \\
\text { at this point in time." }\end{array}$ \\
\hline Understandability & 2 & $\begin{array}{l}\text { "[I provide] packaged information to executives. They don't have } \\
\text { much time, so information needs to be simple and easy to } \\
\text { understand." }\end{array}$ \\
\hline Accessibility & 1 & $\begin{array}{l}\text { "Accessibility is important from the point of view of IP rights, } \\
\text { licences or purchases, [whether or not we have access to the } \\
\text { information and the technology]." }\end{array}$ \\
\hline Objectivity & 7 & $\begin{array}{l}\text { "Objectivity [is especially important for] information that is usually } \\
\text { questioned and examined." }\end{array}$ \\
\hline Accuracy & 1 & $\begin{array}{l}\text { "What you would always look for in a lead, first of all in terms of } \\
\text { intrinsic qualities is accuracy, accurate in the sense that it does fit } \\
\text { and represents the answer we are looking for." }\end{array}$ \\
\hline Uniqueness & 5 & $\begin{array}{l}\text { "So if we are after a really disruptive technology opportunity, then } \\
\text { uniqueness is going to be of relevance, because that uniqueness is } \\
\text { going to give us maybe something others don't do or didn't guess." }\end{array}$ \\
\hline
\end{tabular}


How to Measure Technology Intelligence?

\begin{tabular}{|l|c|l|}
\hline & 8 & $\begin{array}{l}\text { "If 'unique' refers to a technology then that's not important. But if } \\
\text { 'uniqueness' refers to a way of applying it, then maybe that's a bit } \\
\text { more important." }\end{array}$ \\
\hline Clarity & 1 & "I don't know how different clarity is from understandability." \\
\hline Verifiability & 7 & $\begin{array}{l}\text { "Verifiability is very hard. [With TI] you are talking about future } \\
\text { research projects that are identifying future needs or trying to solve } \\
\text { future problems using different paradigms." }\end{array}$ \\
\cline { 2 - 3 } & 3 & $\begin{array}{l}\text { "If you tell the senior management something and he asks 'what' or } \\
\text { 'why', we should have proofs for that, to make them trust you." }\end{array}$ \\
\hline Granularity & 2 & $\begin{array}{l}\text { "When dealing with strategy, we have to accept that it will not have } \\
\text { the granularity it will have in operations. We are not dealing with the } \\
\text { decimal points, or else it will not be called strategy." }\end{array}$ \\
\hline
\end{tabular}

Table 2: Comments from interviewees about IQ metrics 
Int. J. Technology Intelligence and Planning, Vol. x, No. x, xхxx

\begin{tabular}{|c|c|c|c|c|c|c|c|c|}
\hline \multirow[t]{2}{*}{ Company } & \multirow[t]{2}{*}{ Interviewee } & \multirow[t]{2}{*}{ Role/characteristics } & \multirow[t]{2}{*}{ Modes of TI } & \multirow[t]{2}{*}{ Measures used } & \multicolumn{4}{|c|}{ Metrics-type } \\
\hline & & & & & Activity & Outcome & $\begin{array}{l}\text { Project- } \\
\text { specific }\end{array}$ & $\begin{array}{l}\text { Firm- } \\
\text { wide } \\
\text { metrics }\end{array}$ \\
\hline \multirow[t]{4}{*}{1} & \multirow{4}{*}{$\begin{array}{l}\text { Open innovation } \\
\text { manager }\end{array}$} & \multirow{4}{*}{$\begin{array}{l}\text { Work across functions to support different } \\
\text { business functions, in charge of technology } \\
\text { scouting, facilitate technology acquisition } \\
\text { and create potential for disruptive innovation. }\end{array}$} & \multirow[t]{4}{*}{ Target, scan } & Number of leads & Q & & प & \\
\hline & & & & $\begin{array}{l}\text { Number of leads incorporated } \\
\text { into business }\end{array}$ & & $\overline{0}$ & प & \\
\hline & & & & Rate of lead impact & & $\bar{Q}$ & $\overline{0}$ & \\
\hline & & & & Impact on turnover & & $\overline{0}$ & & $\bar{\square}$ \\
\hline 2 & Strategy advisor & $\begin{array}{l}\text { Long-term strategy planning, scan for game- } \\
\text { changing technology, technology } \\
\text { foresighting and landscaping from an } \\
\text { industry point of view. }\end{array}$ & Scan & $\begin{array}{l}\text { Financial benefits of the } \\
\text { projects }\end{array}$ & & 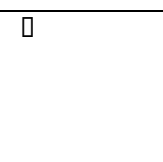 & $\square$ & \\
\hline \multirow[t]{4}{*}{3} & \multirow{4}{*}{$\begin{array}{l}\text { Team leader - } \\
\text { Structural design } \\
\text { \& prototype }\end{array}$} & \multirow[t]{4}{*}{$\begin{array}{l}\text { Technology research, roadmap and } \\
\text { acquisition. }\end{array}$} & \multirow[t]{4}{*}{ Target } & $\begin{array}{l}\text { Technical specification target } \\
\text { met }\end{array}$ & & $\bar{Q}$ & $\overline{0}$ & \\
\hline & & & & Networks gained & $\bar{\square}$ & & & 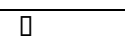 \\
\hline & & & & Number of ideas generated & प & & $\square$ & \\
\hline & & & & Number of patents reviewed & प & & प & \\
\hline \multirow[t]{2}{*}{4} & \multirow{2}{*}{$\begin{array}{l}\text { Head of innovation } \\
\text { (previous) }\end{array}$} & \multirow{2}{*}{$\begin{array}{l}\text { Technology scouting, scanning, landscaping } \\
\text { in a specific geographical focus. }\end{array}$} & \multirow[t]{2}{*}{ Target, scan } & Geographical coverage & & $\bar{Q}$ & & $\overline{0}$ \\
\hline & & & & Number of leads assessed & $\bar{Q}$ & & $\bar{Q}$ & \\
\hline
\end{tabular}

Copyright (C) 2016 Inderscience Enterprises Ltd. 
How to Measure Technology Intelligence?

\begin{tabular}{|c|c|c|c|c|c|c|c|c|}
\hline & & & & $\begin{array}{l}\text { Number of leads that turned } \\
\text { into collaborations }\end{array}$ & & Q & Q & \\
\hline \multirow[t]{6}{*}{5} & \multirow[t]{6}{*}{ Seeker } & \multirow{6}{*}{$\begin{array}{l}\text { Technology scouting for science and } \\
\text { technology platforms, cross-industry learning } \\
\text { and internal intelligence gathering. }\end{array}$} & \multirow[t]{6}{*}{$\begin{array}{l}\text { Scan, trawl, } \\
\text { mine }\end{array}$} & $\begin{array}{l}\text { Number of papers and journals } \\
\text { read }\end{array}$ & 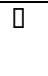 & & $\bar{Q}$ & \\
\hline & & & & Networks gained & $\overline{0}$ & & & प \\
\hline & & & & Number of patents reviewed & $\overline{0}$ & & प & \\
\hline & & & & Level of technology absorption & Q & & & प \\
\hline & & & & Number of leads & प & & प & \\
\hline & & & & Geographical spread & Q & & & प \\
\hline \multirow[t]{3}{*}{6} & \multirow[t]{3}{*}{ Staff officer } & \multirow[t]{3}{*}{$\begin{array}{l}\text { Acquire technology with current partners } \\
\text { based on internal needs. }\end{array}$} & \multirow[t]{3}{*}{ Target } & $\begin{array}{l}\text { Number of internal papers } \\
\text { published }\end{array}$ & & $\bar{Q}$ & $\bar{\square}$ & \\
\hline & & & & $\begin{array}{l}\text { Breadth of external networks } \\
\text { consulted }\end{array}$ & $\bar{\square}$ & & $\overline{0}$ & प \\
\hline & & & & Geographical spread & ए & & & प \\
\hline 7 & $\begin{array}{l}\text { European funding } \\
\text { coordinator }\end{array}$ & $\begin{array}{l}\text { Work across sections to identify technology } \\
\text { development activities, prepare proposals for } \\
\text { funding and innovation management. }\end{array}$ & Target, mine & Number of leads & $\bar{Q}$ & & $\overline{0}$ & \\
\hline 8 & $\begin{array}{l}\text { External research } \\
\text { programme } \\
\text { manager }\end{array}$ & $\begin{array}{l}\text { Coordinate university research, control } \\
\text { budget and contracts. Projects focus on } \\
\text { fundamental research. }\end{array}$ & Scan & $\begin{array}{l}\text { Do not actively monitor (Get to } \\
\text { know the progress via review } \\
\text { meetings and updates) }\end{array}$ & & & & \\
\hline 9 & & $\begin{array}{l}\text { Lead breakthrough technology research in } \\
\text { process equipment and develop new process }\end{array}$ & $\begin{array}{l}\text { Target, trawl, } \\
\text { mine }\end{array}$ & $\begin{array}{l}\text { Percentage of turnover as a } \\
\text { result of R\&D innovation }\end{array}$ & & प & & प \\
\hline
\end{tabular}


Y. W. Loh, L. Mortara

\begin{tabular}{|c|c|c|c|c|c|c|c|c|}
\hline & $\begin{array}{l}\text { Technology } \\
\text { innovation } \\
\text { manager }\end{array}$ & $\begin{array}{l}\text { concepts at the front end of technological } \\
\text { innovation. }\end{array}$ & & $\begin{array}{l}\text { Number of top innovations in a } \\
\text { country that came from the } \\
\text { company }\end{array}$ & & प & & प \\
\hline \multirow[t]{4}{*}{10} & \multirow{4}{*}{$\begin{array}{l}\text { Software system } \\
\text { manager }\end{array}$} & \multirow{4}{*}{$\begin{array}{l}\text { Act as innomediary, monitor information that } \\
\text { comes from publications or developments in } \\
\text { industry, enter new scholarly materials into } \\
\text { company database. }\end{array}$} & \multirow{4}{*}{$\begin{array}{l}\text { Target, trawl, } \\
\text { mine }\end{array}$} & Number of entries in database & Q & & प & [ \\
\hline & & & & $\begin{array}{l}\text { How long does it take for an } \\
\text { article from being published to } \\
\text { enter the database }\end{array}$ & & $\overline{0}$ & प & \\
\hline & & & & Impact on project funding & & Q & Q & \\
\hline & & & & Number of journals reviewed & $\square$ & & 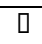 & \\
\hline \multirow[t]{5}{*}{11} & \multirow{5}{*}{$\begin{array}{l}\text { Technology } \\
\text { specialist }\end{array}$} & \multirow{5}{*}{$\begin{array}{l}\text { Connect to technology startups to be brought } \\
\text { in based on their value, develop technology } \\
\text { trends and awareness. }\end{array}$} & \multirow[t]{5}{*}{ Scan } & Number of leads & Q & & प & \\
\hline & & & & $\begin{array}{l}\text { Number of leads that turned } \\
\text { into collaborations }\end{array}$ & & 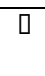 & प & \\
\hline & & & & Value of projects brought in & & प & प & \\
\hline & & & & $\begin{array}{l}\text { Success rate of incorporating } \\
\text { projects }\end{array}$ & & प & & प \\
\hline & & & & Geographical coverage & प & & & $\overline{0}$ \\
\hline \multirow[t]{3}{*}{12} & \multirow{3}{*}{$\begin{array}{l}\text { Assembly } \\
\text { commodity } \\
\text { strategy lead }\end{array}$} & \multirow{3}{*}{$\begin{array}{l}\text { Generate technology ideas and capabilities } \\
\text { with research centres, universities and } \\
\text { suppliers, also in charge of commodity } \\
\text { strategy. }\end{array}$} & \multirow[t]{3}{*}{$\begin{array}{l}\text { Target, trawl, } \\
\text { mine }\end{array}$} & $\begin{array}{l}\text { Success rate of incorporating } \\
\text { projects }\end{array}$ & & $\overline{0}$ & & $\overline{0}$ \\
\hline & & & & $\begin{array}{l}\text { Technical specification target } \\
\text { met }\end{array}$ & & 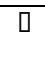 & $\overline{0}$ & \\
\hline & & & & Level of technology absorption & प & & & $\overline{0}$ \\
\hline
\end{tabular}

Table 3: Overview of the key metrics reported by the interviewees 
How to Measure Technology Intelligence?

Mortara, L., R. Thomson, C. Moore, K. Armara, C. Kerr, R. Phaal, and D. Probert. 2010. "Developing a Technology Intelligence Strategy at Kodak European Research: Scan and Target." Research - Technology Management 53 (4):27-38. 